\title{
Fundamentos da Economia, Mercado Financeiro e Intenção de Voto: As Eleições Presidenciais Brasileiras de 1994, 1998 e 2002
}

Lucio Rennó

Anthony P. Spanakos

\section{INTRODUÇÃO}

m economias emergentes, crescimento econômico necessariamen$\triangle$ te passa pela dependência de capital estrangeiro. Em uma época em que o fluxo internacional de capitais é intenso e praticamente desregulado, acentua-se a influência de atores do mercado financeiro em processos decisórios domésticos (Bernhard e Leblang, 2001; Clark e Hallerberg, 2000). Surpreendentemente, há uma lacuna nas literaturas nacional e internacional sobre como a política doméstica de países em desenvolvimento é afetada pelo mercado financeiro internacional ${ }^{1}$. Este artigo pretende dar um primeiro passo na direção de suprir tal lacuna, analisando o impacto da taxa de câmbio, de índices de risco-país e de indicadores da bolsa de valores nas intenções de voto para presidente no Brasil contemporâneo. Além desses indicadores, o impacto de variáveis econômicas, tradicionalmente analisadas em estudos sobre economia e eleições, também será avaliado (Hibbs, 1987; Eulau e Lewis-Beck, 1985).

As eleições presidenciais brasileiras de 1994, 1998 e 2002 oferecem excelente oportunidade para a realização de tal estudo. Primeiro, por ser um período marcado por duas vitórias consecutivas de um presidente com propostas favoráveis à abertura do mercado nacional, privatiza-

DADOS - Revista de Ciências Sociais, Rio de Janeiro, Vol. 49, nํ1, 2006, pp. 11 a 40. 
ção de empresas públicas e estabilização da economia - políticas centrais de uma agenda de reforma fortemente apoiada por instituições financeiras internacionais e orientada por uma lógica considerada neoliberal (Haggard e Kaufman, 1992). Por outro lado, em 2002, a oposição comandada pelo Partido dos Trabalhadores - PT chega ao poder com um discurso que combinava a manutenção de contratos com propostas de geração de emprego. Questões econômicas estão no âmago do debate eleitoral em todas as eleições presidenciais recentes. Desta feita, como a economia afetou a alternância de partidos no poder, esta é questão central para o debate sobre eleições no Brasil.

Um segundo fator interessante desse período é o crescente destaque dado pela mídia à relação entre intenção de voto e indicadores do mercado financeiro nacional e internacional. Temas como risco-país (spread do C-Bond), índices de bolsas de valores e taxa de câmbio passaram a ser tratados diariamente pela mídia nas eleições de 1998 e 2002. A despeito da crescente saliência desses temas no debate eleitoral, o real impacto dessas variáveis nas intenções de voto do eleitor brasileiro ainda não foi verificado empiricamente.

Outra questão diz respeito especificamente aos indicadores dos fundamentos da economia. O desemprego parece ter ganhado mais destaque do que a inflação no debate eleitoral de $2002^{2}$. Conforme previsto pela Curva de Phillips, uma vez controlada a inflação (e como conseqüência direta de medidas que resfriam a produção econômica e a circulação de moeda), recessão e propostas de geração de emprego passam a ser o eixo da discussão sobre economia (Stokes, 2001; 2001a; 2001b). O caso brasileiro em 2002 não se distancia dessa lógica. Portanto, um modelo que vise a explicar intenções de voto baseado em variáveis econômicas não pode ignorar o papel central que o combate à inflação e ao desemprego teve no Brasil recente.

De forma mais específica, este artigo pretende oferecer respostas para as seguintes perguntas: qual é a relação causal entre indicadores do mercado financeiro e fundamentos da economia, por um lado, e intenções de voto, por outro? O que determina o quê? Na essência dessa discussão está a questão da simultaneidade entre variáveis econômicas e políticas. Além disso, outro tema explorado é a direção do impacto dos distintos indicadores econômicos nas intenções de voto. Ou seja, como as intenções de voto em candidatos do governo e oposição são distintamente afetadas pelos diversos indicadores econômicos. 
Susan Stokes (2001) propõe uma discussão bastante inovadora acerca do impacto da economia em intenções de voto. Stokes argumenta que o voto econômico retrospectivo ${ }^{3}$, no qual eleitores punem candidatos do governo quando a economia vai mal, não é o único cálculo eleitoral possível, principalmente em países que atravessam profundos processos de reforma econômica. Para a autora, seguindo ensinamentos anteriores de Downs (1957) e Fiorina (1981), avaliações prospectivas combinam-se com avaliações retrospectivas no momento do cálculo eleito$\mathrm{ral}^{4}$. As combinações diferenciadas entre elementos retrospectivos e prospectivos no cálculo eleitoral acabam por gerar diversos padrões de voto. É essa a essência da inovação teórica proposta por Stokes. Este artigo aplica sua argumentação à análise do caso brasileiro.

O artigo está organizado da seguinte forma. A próxima seção enfoca o impacto de indicadores do mercado financeiro e fundamentos da economia em intenções de voto. Na terceira seção, aplicamos o arcabouço teórico proposto por Stokes ao caso brasileiro. Em seguida, derivamos da discussão teórica hipóteses empiricamente verificáveis. A quinta parte descreve o banco de dados. Segue-se daí a apresentação dos resultados. Ao cabo, oferecemos um resumo dos achados e mencionamos possíveis implicações dos mesmos para a relação entre eleitores e eleitos no Brasil.

\section{MERCADO FINANCEIRO E FUNDAMENTOS DA ECONOMIA}

O impacto da economia na política, até muito recentemente, limitava-se à análise de variáveis relacionadas aos fundamentos da economia (crescimento, desemprego e inflação). Contudo, nos últimos anos, tem-se notado um aumento da saliência de indicadores do mercado financeiro no debate eleitoral. Tanto fundamentos da economia quanto o mercado financeiro, agora, parecem dividir o espaço de discussão sobre o impacto da economia nas eleições. Em termos de modelagem econométrica, ignorar algum desses aspectos é incorrer em erro de especificação. Em termos substantivos, ignorar algum desses fatores é contar uma história incompleta. Infelizmente, a maior parte dos estudos sobre economia e eleições ainda não incorporou o impacto de indicadores do mercado financeiro em análises eleitorais, principalmente em países em desenvolvimento.

A crescente importância de temas relacionados ao mercado financeiro nacional e internacional deve-se a dois fatores principais. Primeiro, há 
uma crescente internacionalização e flexibilização dos fluxos de capital, que não existia na magnitude de hoje a 10 anos atrás. Segundo, atores ligados a esse setor ganharam influência na política doméstica, e essa influência deve ser ainda mais visível onde a necessidade de obtenção de investimento externo é imprescindível para o desenvolvimento econômico. Portanto, a mudança na agenda de discussão sobre temas econômicos não se deve ao acaso. Ela é fruto de mudanças ocorridas no sistema financeiro internacional e na abertura das economias nacionais, outrora bem mais fechadas à competição externa.

Tendo em vista que a análise da relação entre economia e eleições em países economicamente desenvolvidos já incorpora tanto os fundamentos da economia quanto fatores ligados ao mercado financeiro em suas análises eleitorais, é possível aplicar algumas dessas abordagens ao estudo de países em desenvolvimento. Em trabalhos anteriores, indicadores sobre os fundamentos da economia nacional, como inflação e desemprego, eram os pontos centrais da análise (Eulau e Lewis-Beck, 1985; Lewis-Beck, 1988; Echegaray, 1995). A relação entre esse conjunto de variáveis e intenção de voto era tida como bastante evidente. Quanto mais alta a inflação, quanto maior o desemprego, quanto mais baixos os salários, mais baixa também é a popularidade do governo. Isso se traduz, conseqüentemente, em queda nas intenções de voto para candidatos do governo.

Em suma, quanto pior o desempenho do governo na administração da economia, pior sua avaliação pela população e mais tênues suas chances de se manter no poder. Segundo essa visão, eleitores decidem seus votos em parte baseados em avaliações retrospectivas do desempenho de seus governantes (Fiorina, 1981). Pode-se dizer que o voto retrospectivo é tido como o padrão normal de decisão eleitoral em um regime democrático, pois está fortemente associado à idéia de accountability ${ }^{5}$. A direção causal é clara: fatores econômicos afetam intenções de voto.

Por outro lado, a ciência política também parece ter incorporado em seus estudos o impacto do aumento indiscutível na fluidez dos fluxos de capital externo e a crescente influência de variáveis do mercado financeiro internacional em assuntos domésticos. Há diversos autores que têm apontado para a crescente influência de atores do mercado financeiro internacional nos rumos da política doméstica (Leblang, 1997; Kaufman e Segura-Ubiergo, 2001; Clark e Hallerberg, 2000; Basinger e Hallerberg, 2004). Em decorrência, indicadores de taxa de 
câmbio, medidas de risco-país e índices de bolsas de valores passam a ganhar destaque na discussão sobre eleições (Gleisner, 1992; Berry, Elliott e Harpham, 1996; Alesina et alii, 1997; Freeman et alii, 2000; Hays et alii, 2000; Bernhard e Leblang, 2001).

Uma contribuição importante dessa nova literatura é a idéia de que há uma relação causal recíproca entre indicadores do mercado financeiro e voto (Bernhard e Leblang, 2001). O mercado financeiro reage mal à incerteza gerada por eleições (idem; Borsani, 2001). Eleições são momentos de mudança que sempre envolvem riscos e por isso geram trepidação nos indicadores do mercado financeiro. Contudo, a reação deste deverá ser mais aguda quando a perspectiva de mudança em uma ordem favorável aos seus interesses é maior. Partidos de esquerda normalmente são associados a políticas econômicas heterodoxas ${ }^{6}$. Portanto, quando um candidato de esquerda ganha apoio eleitoral, sinalizando a possibilidade de mudança na política econômica de um governo que segue a cartilha da ortodoxia econômica, isso acaba por afetar avaliações de risco de analistas financeiros. Parece claro que variações em intenções de voto influenciam indicadores financeiros.

Por outro lado, indicadores do mercado financeiro podem também afetar a popularidade de governantes e intenções de voto (Bernhard e Leblang, 2001; Berry et alii, 1996). É de se esperar que atores do mercado financeiro tenham preferências por candidatos que defendam propostas políticas que os beneficiem. Quando candidatos do governo, favoráveis ao mercado, a parecem bem em pesquisas de opinião, isso não deve gerar oscilações nos indicadores financeiros. Tais indicadores devem se manter estáveis e positivos e provavelmente não se tornam tema para uso político durante a campanha, a não ser para beneficiar o governo. Por outro lado, quando há crescimento das intenções de voto em candidatos contrários ao mercado, isso aumenta a incerteza de investidores e pode gerar instabilidade e queda nos indicadores financeiros. A instabilidade dos indicadores financeiros, por sua vez, pode se tornar tema político a ser explorado durante a campanha eleitoral e vir a impactar a disputa eleitoral.

Conforme Bernhard e Leblang (2001), o impacto dos indicadores financeiros provavelmente é mais visível quando estes oscilam negativamente. Ou seja, o mecanismo causal da relação entre intenção de voto e indicadores financeiros tem diversos momentos. Primeiro, pioras nas avaliações de risco-país ou queda na bolsa de valores podem ser credi- 
tadas ao crescimento nas pesquisas de intenção de voto de candidatos contrários aos interesses do mercado financeiro. Em um segundo momento, o enfraquecimento dos indicadores financeiros pode ser utilizado como um fato político pelo candidato governista. A deterioração dos indicadores financeiros pode ser creditada à postura de um candidato específico e isso pode impactar intenções de voto nesse candidato em pesquisas futuras. A constante menção da fragilidade dos indicadores do mercado financeiro em jornais e na propaganda eleitoral de certos candidatos aumenta a visibilidade desses temas para o eleitor e pode afetar intenções de voto em um momento posterior. Em outras palavras, ocorre primeiro uma assimilação do quadro eleitoral por parte dos atores do mercado financeiro que se reflete nos indicadores financeiros. Posteriormente, uma vez que a reação do mercado financeiro se torna pública e é usada eleitoralmente por atores políticos, esta pode vir a impactar as intenções de voto.

\section{CÁLCULOS ELEITORAIS EM PAÍSES EM DESENVOLVIMENTO}

O ganho em complexidade na relação entre economia e eleições afetou diretamente uma nova agenda de pesquisas proposta por Stokes (2001; 2001a; 2001b). Para ela, ambientes que atravessaram processos recentes de ajuste econômico e reforma política permitem o surgimento de diversos tipos de cálculo eleitoral, em que componentes retrospectivos podem ser combinados com elementos prospectivos. Além do voto retrospectivo, eleitores podem também realizar um cálculo intertemporal, um cálculo de exoneração, e ter uma postura oposicionista ou ainda distributivista.

Um elemento-chave nessa nova visão é que eleitores podem tolerar dificuldades econômicas no presente em nome de recompensas futuras o chamado voto intertemporal, que é aquele em que o eleitor apóia o governo ou seu candidato mesmo quando os indicadores econômicos não apresentam resultados satisfatórios. Na essência do voto intertemporal está a idéia que os eleitores fazem uma análise prospectiva dos candidatos. O eleitor leva em consideração não apenas o desempenho do governo na área econômica, mas avalia as promessas de campanha do candidato do governo e as justificativas dadas pelo governo para possíveis dificuldades econômicas. Candidatos que adotam essa postura argumentam que sacrifícios no presente serão recompensados por ganhos no futuro. Ou seja, o remédio é amargo, mas a cura virá. 
Uma outra lógica de escolha eleitoral passa por culpar regimes anteriores ou fatores externos para o mau desempenho do governo - este é o cálculo de exoneração. O governo não é punido por eleitores porque a culpa pelas dificuldades do presente é creditada a governos anteriores ou ao contexto internacional. Tal estratégia tem mais credibilidade quando empregada em épocas de transição de governos autoritários para democráticos ou de crise global, como durante a crise da dívida.

Outra lógica ainda se refere ao voto puramente oposicionista. Independentemente do que o governo faça, o eleitor que emprega esse cálculo vota sempre contra o governo por motivos partidários, ideológicos ou pessoais. Esse tipo de cálculo, portanto, não é econômico em sua essência. Trata-se de uma forma de decisão não condicionada ao funcionamento da economia.

Outro cálculo é o distributivista, em que pesa de forma mais acentuada a condição pessoal do eleitor do que o estado da economia do país. Nesse caso, o eleitor pune o governo quando sua situação econômica pessoal se mantém estável ou decai, mesmo com melhorias na situação econômica nacional.

O instrumental teórico proposto por Stokes (2001) foi testado em diversos países. A própria autora estuda as eleições peruanas, Adam Pzreworski (2001) analisa a Polônia e, em colaboração com José María Maravall, a Espanha (2001). Um último país europeu analisado seguindo essa mesma lógica é a Alemanha (Anderson e Tverdova, 2001). Na América Latina, além do caso peruano, Jorge Buendía Laredo (2001), analisa o México e Fabian Echegaray e Carlos Elordi (2001), a Argentina. A grande vantagem do modelo proposto por Stokes é o de oferecer uma explicação racional para escolhas que aparentemente podem parecer contraditórias e aleatórias.

Uma análise agregada, em série temporal, nos moldes dos estudos de Stokes e seus colaboradores, ainda não foram realizados no Brasil, o que, obviamente, não quer dizer que não haja estudos importantes sobre o impacto de variáveis econômicas nas decisões de voto em eleições brasileiras. Na verdade, o estudo sobre comportamento eleitoral no Brasil tem larga tradição, mas todos os estudos anteriores utilizaram exclusivamente dados de surveys e fizeram análises no plano individual para entender o impacto de variáveis econômicas em escolhas eleitorais. 
Carreirão (2002), Meneguello (1994), Mendes e Venturi (1994), Camargos (2001), entre outros, já testaram diversas hipóteses sobre como a economia afeta escolhas eleitorais. Mais importante ainda, todos indicam que variáveis econômicas influenciam escolhas eleitorais, ao lado de avaliações baseadas em identidades partidárias (Camargos, 2001) e em ideologia (Singer, 2000). Ou seja, estudos agregados, como os propostos por Stokes, são plenamente aplicáveis ao Brasil tendo em vista que no plano individual já foi comprovado que fatores econômicos afetam o voto. O enfoque agregado proposto aqui, portanto, complementa os achados de estudos anteriores que utilizam dados individuais ${ }^{7}$.

O Brasil, como o caso do Peru, México e Argentina, é um país que atravessou profundas mudanças institucionais e econômicas nas três últimas décadas. É um país que passou de uma inflação mensal de três dígitos para uma de apenas um dígito. Além disso, é um país que se abriu para o mercado internacional e que privatizou suas empresas estatais. Por fim, é um país que encontra dificuldades para gerar empregos e produzir crescimento econômico. Por estes motivos, é um caso muito apropriado para o estudo dos diversos cálculos eleitorais propostos por Stokes.

Por exemplo, a lógica intertemporal enquadra-se bem às eleições de 1994. Nela, o candidato a presidente apoiado pelo governo usa uma retórica contrária a choques ou mudanças milagrosas em seu governo. $\mathrm{O}$ processo de controle da inflação e as mudanças estruturais necessárias são lentos e graduais e seguidos por tempos de privação econômica. Contudo, rezava a mensagem governista de então, tais dificuldades são passageiras e as transformações estruturais gerarão as bases para um crescimento sustentável da economia.

Também, é importante frisar, o governo colhia os frutos do sucesso de seu plano de estabilização. O controle da inflação apresentava melhorias palpáveis na qualidade de vida dos brasileiros e isso se refletiu no sucesso eleitoral de Fernando Henrique Cardoso. Portanto, em 1994 havia espaço também para uma avaliação retrospectiva da economia além do cálculo intertemporal. A estabilização da economia em si era um bem coletivo e o candidato do governo tirou proveito disso.

Em 1998, a retórica passou a ser de exoneração. O governo culpava a situação internacional pelos problemas da economia. A crise na Rússia e a falta de confiança generalizada de investidores internacionais em mercados em desenvolvimento foram as principais justificativas para 
o pífio desempenho econômico que se acentuava em fins de 1998. Na verdade, o argumento da internacionalização do mercado financeiro e a famosa crise na Rússia, que ocuparam papel de destaque na mídia então, foram usados como justificativas para problemas nacionais e vieram possivelmente a ajudar Fernando Henrique em sua campanha (Miguel, 1999). É fundamental ressaltar aqui que a abordagem de Stokes (2001), portanto, abre uma importante brecha para incorporar indicadores do mercado financeiro no estudo da relação entre economia e voto, embora ela própria e seus colegas não o façam em seus estudos.

Mas, novamente certo elemento retrospectivo ainda tinha espaço em 1998. Não só o governo se valia ainda do sucesso de seu plano de estabilização como também usava o argumento que a administração de Fernando Henrique estava mais preparada para enfrentar as constantes crises da economia internacional. Segundo o argumento governista de então, só o governo Fernando Henrique, que já havia se mostrado eficiente na contenção de diversas crises internacionais, era capaz de proteger o país de novos choques. Portanto, é possível também vislumbrar uma situação em que uma turbulência do mercado financeiro internacional beneficie candidatos do governo.

Já em 2002, a lógica dominante parece ter sido a do voto retrospectivo. Uma vez ganha a batalha contra a inflação, há limites até onde o sucesso do plano de estabilização garantirá retorno eleitoral. Uma vez que a diminuição da inflação se torna o status quo, outros temas passam a ganhar destaque. Susan Stokes (idem) refere-se a esse fenômeno como paradoxo do sucesso. O desemprego, e não mais a inflação, passa a ter destaque no debate eleitoral brasileiro. O candidato do governo é afetado negativamente pelos fracos indicadores nessa área e pela piora na qualidade de vida do eleitor brasileiro. Em suma, o candidato governista paga o preço ao ser derrotado pelo principal candidato da oposição. Uma decorrência direta de cálculo retrospectivo dos eleitores. Portanto, o voto retrospectivo parece estar na essência do processo de alternância no poder ocorrido em 2002 e tão importante para o fortalecimento da democracia no Brasil.

A idéia da curva de Phillips - na qual, após o controle da inflação, temas relacionados ao crescimento econômico, como desemprego e investimento, naturalmente passam a dominar a agenda econômica - parece se encaixar como uma luva ao caso brasileiro pós-1994 ${ }^{8}$. Um fenômeno que ocorreu nas eleições de 2002 foi o deslocamento da agenda 
de discussão sobre a economia brasileira do problema da inflação para temas relacionados ao desemprego, mercado financeiro e investimento externo.

Cabe ressaltar que em 1998, já se fazia sentir a influência do mercado internacional e dos fluxos de capital estrangeiro no debate eleitoral, quando o medo da desvalorização do Real, a mudança nas taxas de juros e as repercussões da crise na Rússia ameaçavam a reeleição de Fernando Henrique. Já em 2002, a discussão sobre fatores relacionados ao mercado financeiro tornou-se alvo, quase que central, da mídia (Spanakos, 2002; Williamson, 2002). A tônica dessa cobertura era que o mercado financeiro reagia negativamente ao aumento das intenções de voto em Luiz Inácio Lula da Silva. A iminente vitória da oposição e de um partido de origem socialista, e a incerteza que esse fato gerava com relação a que rumo seria dado à economia nacional, levava à formação de expectativas negativas no mercado financeiro, que se refletiam nos índices e taxas mencionadas acima. A folgada margem de intenção de votos de Lula nas pesquisas (em uma possível leitura dos agentes do mercado financeiro) indicava não apenas a possibilidade de mudanças nas políticas macroeconômicas do governo, mas de mudanças que poderiam ser desfavoráveis ao mercado financeiro 9 . $\mathrm{Ou}$ seja, o cenário eleitoral sem dúvida afetou os cálculos dos analistas de mercado. Contudo, Lula ganhou a eleição com folga, e isto levanta a suspeita de que os indicadores do mercado financeiro não tiveram impacto suficientemente forte no processo eleitoral para alterar o resultado final da eleição, o que não significa que o impacto eleitoral de atores do mercado financeiro deva ser ignorado. A preocupação do mercado influenciou as escolhas de atores políticos-chave durante a campanha eleitoral. O PT teve que repetidas vezes afirmar que não haveria "quebra de contratos"; inclusive por escrito, como ficou evidenciado no documento Carta ao Povo Brasileiro, no qual o partido comunicava seu comprometimento com a manutenção da estabilidade macroeconômica e o respeito a contratos feitos durante o governo Fernando Henrique. Além disso, a incerteza do mercado gerada pela iminente vitória eleitoral de Lula inquestionavelmente foi utilizada pela campanha de José Serra, em proveito próprio, na tentativa de reverter o quadro de intenção de voto desfavorável à sua chapa.

A questão que se coloca então é: há uma relação causal recíproca, de mão dupla, entre variação em indicadores do mercado financeiro e variação em intenções de voto? Avaliações do mercado financeiro podem ser afe- 
tadas negativamente pelo crescimento em pesquisas de opinião de candidatos com propostas contrárias ao interesse do mercado financeiro ou cujas propostas de reforma não sejam claras. Posteriormente, a queda dos indicadores financeiros pode ser creditada por seus adversários ao crescimento de um candidato específico nas pesquisas de voto. $\mathrm{O}$ argumento utilizado por um candidato adversário é que votar em certo candidato, que tradicionalmente tenha se colocado contrário à agenda de instituições financeiras, gera instabilidade econômica e afeta negativamente a economia. Tal argumento pode vir a repercutir em intenções de voto, ainda mais quando é noticiado pelos meios de comunicação e repetido ad nauseum em propagandas eleitorais.

Com base nos argumentos de Stokes e na constatação teórica e empírica sobre a crescente influência do mercado financeiro na política doméstica, o impacto da economia em intenções de voto parece ser muito mais complexo em ambientes que estejam em profunda reforma econômica. Alguns aspectos da economia ganharam destaque no debate eleitoral em anos recentes, enquanto outros aparentemente passaram para segundo plano. Além disso, a direção causal entre economia e política parece ter se tornado ainda mais complexa. Todas essas questões estão abertas a testes empíricos no Brasil, principalmente quando dados agregados em série temporal são usados.

\section{HIPÓTESES}

Conforme foi dito acima, há diversos vetores causais na relação entre intenção de voto, fundamentos da economia e indicadores do mercado financeiro. A partir dessa discussão, derivamos algumas hipóteses sobre a relação entre economia e voto.

Hipótese 1: analistas de mercado e investidores levam em consideração a disputa eleitoral quando definem suas estratégias de investimento. Não restam dúvidas, portanto, que intenções de voto devem afetar indicadores do mercado financeiro como o spread do C-bond, a bolsa de valores e a taxa de câmbio ${ }^{10}$.

Mais precisamente, e conforme a literatura, o crescimento de candidatos de esquerda nas pesquisas de intenção de voto deve levar a quedas nos indicadores do mercado financeiro. Já o mercado financeiro deverá responder favoravelmente ao crescimento de candidatos que apóiam uma agenda neoliberal de reformas políticas, o que, no caso brasileiro, é representado pelos candidatos governistas em 1994, 1998 e 2002. Por- 
tanto, a hipótese 1 desdobra-se em duas sub-hipóteses: 1a) o índice do C-bond, a bolsa de valores e a taxa de câmbio deverão sofrer impacto negativo do crescimento das intenções de voto em candidatos do PT, no caso Lula; e 1b) os índices do mercado financeiro deverão sofrer impacto positivo com o crescimento de candidatos governistas, no caso Fernando Henrique Cardoso e José Serra.

A hipótese 2, por outro lado, baseia-se na idéia de que há ainda poucas evidências empíricas que indicadores do mercado financeiro influenciam escolhas eleitorais. Não há dúvida que indicadores da bolsa de valores e de risco-país têm ganhado mais e mais atenção dos meios de comunicação e de propagandas políticas; resta ver se esse crescente destaque impactou intenções de voto ou se tais fatores ainda são secundários nas escolhas de eleitores brasileiros. A hipótese 2, portanto, pode ser resumida da seguinte forma: intenções de voto para presidente não deverão sofrer impacto decisivo dos indicadores financeiros.

Caso a hipótese 2 seja refutada pelos dados, indicando haver um impacto eleitoral dos indicadores financeiros, então é necessário prever qual a direção deste impacto. Com base na discussão teórica anterior e na análise de conjuntura no Brasil, intenções de voto para candidatos governistas são beneficiadas por melhorias nos indicadores financeiros. Já o candidato da oposição é prejudicado por melhorias nos indicadores financeiros. Finalmente, se houver impacto dos indicadores financeiros nas escolhas eleitorais, este impacto deverá ser defasado no tempo. Como foi discutido anteriormente, o impacto dos indicadores financeiros só ocorre em um segundo momento, após esses indicadores terem sido eles próprios afetados pela competição eleitoral em um primeiro momento.

Em resumo, as hipóteses 1 e 2 argumentam que os indicadores financeiros são bastante sensíveis no curto prazo às intenções de voto nos distintos candidatos e tais reações são diferenciadas por candidato. Já o impacto dos indicadores financeiros nas intenções de voto, ocorre com um atraso no tempo.

Na hipótese 3 voltamos nossa atenção para o papel de variáveis ligadas aos fundamentos da economia. A hipótese é que intenções de voto para presidente serão afetadas no curto prazo por indicadores dos fundamentos da economia, tais como inflação e desemprego. Os estudos em âmbito individual no Brasil não deixam dúvidas que os fundamentos da economia, principalmente inflação, influenciam escolhas eleitorais. 
Os dados agregados devem confirmar esse fato já documentado no plano individual.

Essa hipótese também se desdobra em outras duas sub-hipóteses, ambas embasadas na idéia de que intenções de voto em distintos candidatos são afetadas diferentemente pelo estado da economia. O impacto dos indicadores econômicos nas intenções de voto em candidatos da oposição deve ser diametralmente oposto ao impacto nas intenções de voto nos candidatos do governo. No caso brasileiro, a sub-hipótese 3a defende que pioras no estado da economia, como aumento na inflação e no desemprego, beneficiam Lula. A sub-hipótese $3 \mathrm{~b}$ argumenta que melhorias na economia beneficiam os candidatos do governo, Fernando Henrique Cardoso e José Serra. De fato, se a hipótese 3 e seu conjunto de sub-hipóteses se confirmarem, isso gerará evidências de que predomina no Brasil um voto de caráter retrospectivo.

Contudo, se a hipótese 3 não se confirmar, isso indica que o eleitor pode estar empregando outro cálculo eleitoral que não o retrospectivo no momento de escolha do seu candidato. Conforme discutido anteriormente, há diversos outros cálculos eleitorais possíveis que podem servir de base para explicações alternativas às defendidas na hipótese 3 (Stokes, 2001). Se predominar um cálculo intertemporal, melhorias na economia no presente devem ter efeito negativo no voto em candidatos do governo e positivo no voto em candidatos da oposição. Um voto intertemporal está embasado na idéia de que custos no presente na forma de deterioração da economia são vistos positivamente pelo eleitor, pois estão ligados à expectativa de melhorias no futuro. Em outras palavras, pioras na economia no presente podem resultar em maior apoio aos candidatos do governo. Em contrapartida, melhorias na economia no presente podem ser vistas como sinal de irresponsabilidade do governo e podem ser punidas pelos eleitores com base em expectativas de piora no futuro.

Além do voto intertemporal e do voto retrospectivo, o eleitor pode incorrer em uma lógica de exoneração ou em uma lógica oposicionista, onde o voto é independente da situação da economia. No caso do cálculo de exoneração, não deverá haver relação entre indicadores da economia e voto no governo porque a culpa pelo estado da economia é depositada ou em governos anteriores ou na situação econômica internacional. Já o voto oposicionista é verificado quando não há relação entre o voto em Lula, o candidato da oposição, e variáveis econômicas. A au- 
sência de relação indica que o voto em Lula deverá estar muito mais ligado a vínculos ideológicos, partidários ou pessoais. Ou seja, as predisposições anteriores do eleitor podem atenuar o impacto da economia na escolha eleitoral.

Por fim, com relação ao impacto das intenções de voto nos fundamentos da economia, a idéia dominante na literatura é que a inflação e o déficit tendem a aumentar e o desemprego a cair em anos eleitorais em comparação com anos anteriores, no que ficou conhecido na literatura como electoral business cycle (Nordhaus, 1975; Borsani, 2001), o que mostra que o governo tenta ampliar suas chances eleitorais manuseando políticas econômicas. Portanto, é possível pensar em uma situação em que os fundamentos da economia sejam afetados por intenções de voto. O governo pode tentar alterar o quadro eleitoral adotando determinada política de ajuste econômico. As eleições de 1994, nas quais o governo tirou proveito eleitoral de sua capacidade de implementação de políticas econômicas, podem ser vistas como exemplo crasso de situação em que intenções de voto no candidato do governo afetaram a adoção de uma política econômica de redução da inflação. Deve ficar claro, contudo, que tal situação deverá ocorrer principalmente no que tange a relação entre intenções de voto em candidatos do governo e fundamentos da economia. Candidatos do governo têm maior chance de influenciar políticas públicas que podem alterar a inflação e o desemprego; candidatos da oposição não contam com tais instrumentos. Portanto, a hipótese 4 prevê que inflação e desemprego serão afetados exclusivamente por intenções de voto em candidatos governistas.

Além das variáveis econômicas, o modelo também inclui o impacto de variáveis políticas na decisão de voto do eleitor brasileiro. Isso é uma inovação em relação aos estudos incluídos na coletânea organizada por Stokes. Será avaliado aqui o papel dos debates entre candidatos a presidente, do Horário Gratuito de Propaganda Eleitoral - HGPE e de uma variável que mede popularidade presidencial excluindo o impacto de fatores econômicos, que será descrita detalhadamente adiante. A inclusão de variáveis de cunho político é fundamental para especificar corretamente o modelo explicativo da variação nas intenções agregadas de voto. Um modelo que utliza apenas variáveis econômicas para explicar um fenômeno político, ignorando fatores políticos, está, sem sombra de dúvidas, incorretamente especificado. Este é um problema grave, pois erros de especificação não acarretam apenas ineficiência na estimação (erros-padrão inflados), mas também vieses nos coeficien- 
tes estimados. Os estudos de Stokes e seus colegas sofrem desse grave mal.

Tanto o HGPE quanto os debates demonstram o profissionalismo dos distintos candidatos na condução de suas campanhas eleitorais. Ambos os fatores, HGPE e debates, têm caráter conjuntural, peculiar a cada candidato em cada eleição. Portanto, as variáveis políticas enfocam os fatores conjunturais nas intenções de voto ${ }^{11}$.

\section{DADOS}

O banco de dados usado é composto por séries temporais da aferição de intenção de voto para candidatos a presidente tendo como unidade de observação cada pesquisa eleitoral realizada pelos três maiores institutos de pesquisa do Brasil (Ibope, Datafolha e Vox Populi) em cada um dos anos eleitorais. O banco de dados contém a porcentagem declarada de voto, em pergunta estimulada, para cada candidato que concorreu a presidente da República nas eleições de 1994, 1998 e 2002. Além disso, foram obtidos pelo site do Instituto de Pesquisa Econômica Aplicada - IPEA e acrescentados ao banco de dados indicadores do mercado financeiro internacional (taxa de câmbio e C-bond), indicadores dos fundamentos da economia nacional (desemprego e inflação) e, ainda, indicadores do mercado financeiro nacional (Índice da Bolsa de Valores de São Paulo) ${ }^{12}$; todos correspondentes a cada dia ou mês da divulgação das pesquisas de intenção de voto ${ }^{13}$.

Para a análise bivariada realizada neste estudo, foram utilizadas 99 pesquisas realizadas em 1994, 1998 e 2002 e para multivariada, foram utilizadas apenas as pesquisas cujos dados disponíveis nos websites do Datafolha, Ibope e Vox Populi continham informações sobre porcentagem de indecisos e eleitores que pretendiam votar em branco ou nulo. Foram aproveitados os resultados de 67 pesquisas. É fundamental incluir como variável dependente no teste multivariado não apenas as porcentagens de votos em Lula e nos dois candidatos do governo no período analisado, ambos do Partido da Social Democracia Brasileira PSDB, como também os votos dos demais candidatos, os eleitores indecisos e aqueles que afirmam votar em branco ou nulo ${ }^{14}$.

\section{ANÁLISE}

Testes de causalidade de Granger bivariados são uma primeira forma de abordar a relação de antecedência causal entre séries temporais dis- 
tintas. O teste de Granger, valendo-se de um teste F de significância estatística, verifica se valores anteriores de uma variável aumentam a capacidade de previsão (forecast) de uma outra variável. A Tabela 1 apresenta os resultados para os testes em que variáveis de indicação de voto em Lula, Fernando Henrique e Serra afetam mudanças nos valores das variáveis econômicas e financeiras. Um valor defasado de até duas pesquisas foi testado para verificar se há um possível efeito retardado das intenções de voto nos indicadores econômicos, conforme sugerido pela discussão teórica.

Fica claro que intenções de voto em Fernando Henrique, mais do que em Lula e Serra, influenciam os valores de diversos indicadores econômicos e permite prever valores da inflação, desemprego, taxa de câmbio, índice da Bovespa e spread do C-bond, afetando diretamente o desempenho da economia. O voto em Serra, por sua vez, não se relaciona com os indicadores econômicos.

No caso de Lula, intenções de voto alteram apenas os valores do C-bond, o que demonstra que o mercado financeiro internacional reage às intenções de voto em Lula. Já indicadores dos fundamentos da economia não são afetados por intenções de voto em Lula, confirmando nossa expectativa de que apenas candidatos do governo, principalmente quando concorrem à reeleição, são os únicos capazes de interferir no andamento da economia.

Na tabela 1 foram testadas as hipóteses 1 e 4, que estabeleciam expectativas teóricas sobre o impacto das intenções de voto em candidatos do governo e da oposição nas variáveis econômicas e financeiras. Passamos agora a testar as hipóteses $2 e 3$, acerca do impacto da economia e do mercado financeiro nas intenções de voto. Para fazer isso usamos uma modelagem um pouco mais complexa do que a empregada acima ${ }^{15}$.

A Tabela 2 apresenta os resultados do teste multivariado SUR (Seemingly Unrelated Regressions) para intenções de voto nas eleições presidenciais de 1994, 1998 e $2002^{16}$. As variáveis dependentes utilizadas estão divididas em cinco equações: a) intenção de voto em Lula; b) intenção de voto em candidatos do governo, que combina Fernando Henrique e Serra; c) intenções de voto em todos os demais candidatos combinadas em uma variável; d) indecisos; e e) intenção de votar em branco ou nulo. Obviamente que tal classificação simplifica a competição eleitoral em cada um dos três anos analisados e leva a certo desperdício de informação que fica claro na variável dependente $C$, em que as 
Fundamentos da Economia, Mercado Financeiro e Intenção de Voto...

Tabela 1

Teste de Granger Bivariado das Intenções de Voto em Indicadores Econômicos:

Brasil, 1994, 1998 e 2002

\begin{tabular}{|c|c|c|c|}
\hline Lula & $\longrightarrow$ & Inflação, lag(1) & $F(1,96)=0,48252054$ \\
\hline Lula & $\longrightarrow->$ & Inflação, lag(2) & $F(2,94)=1,2527164$ \\
\hline Lula & $\longrightarrow$ & Desemprego, $\operatorname{lag}(1)$ & $F(1,96)=0,54137225$ \\
\hline Lula & $\longrightarrow$ & Desemprego, lag(2) & $F(2,94)=0,60749607$ \\
\hline Lula & $\longrightarrow$ & Câmbio, lag(1) & $F(1,96)=2,2935358$ \\
\hline Lula & $\longrightarrow$ & Câmbio, lag(2) & $F(2,94)=1,9744413$ \\
\hline Lula & $->$ & Ibovespa, lag(1) & $F(1,96)=0,47382695$ \\
\hline Lula & $\longrightarrow$ & Ibovespa, lag(2) & $\mathrm{F}(2,94)=1,5473752$ \\
\hline Lula & $\longrightarrow$ & C-Bond, lag(1) & $\mathrm{F}(1,96)=9,6106018^{* * *}$ \\
\hline Lula & $\longrightarrow$ & C-Bond, lag(2) & $F(2,94)=10,271848^{* * *}$ \\
\hline FHC & $->$ & Inflação, lag(1) & $\mathrm{F}(1,96)=5,1150588^{* *}$ \\
\hline FHC & $\longrightarrow$ & Inflação, $\operatorname{lag}(2)$ & $\mathrm{F}(2,94)=6,0242655^{* * *}$ \\
\hline FHC & $\longrightarrow$ & Desemprego, lag(1) & $F(1,96)=1,3784062$ \\
\hline FHC & $->$ & Desemprego, lag(2) & $\mathrm{F}(2,94)=14,821774^{* * *}$ \\
\hline FHC & $->$ & Câmbio, lag(1) & $F(1,96)=0,41221367$ \\
\hline FHC & $\longrightarrow$ & Câmbio, lag(2) & $\mathrm{F}(2,94)=8,2743029^{* * *}$ \\
\hline FHC & $\longrightarrow$ & Ibovespa, lag(1) & $F(1,96)=3,2463137^{*}$ \\
\hline FHC & $\longrightarrow$ & Ibovespa, lag(2) & $\mathrm{F}(2,94)=11,673637^{* * *}$ \\
\hline FHC & $\longrightarrow$ & C-Bond, lag(1) & $\mathrm{F}(1,96)=63,457232^{* * *}$ \\
\hline FHC & $\longrightarrow$ & C-Bond, lag(2) & $\mathrm{F}(2,94)=81,199485^{* * *}$ \\
\hline Serra & $->$ & Inflação, lag(1) & $F(1,96)=0,42916291$ \\
\hline Serra & $\rightarrow>$ & Inflação, $\operatorname{lag}(2)$ & $F(2,94)=0,78110136$ \\
\hline Serra & $\longrightarrow$ & Desemprego, lag(1) & $F(1,96)=0,96158336$ \\
\hline Serra & $\longrightarrow$ & Desemprego, lag(2) & $F(2,94)=0,50107591$ \\
\hline Serra & $\longrightarrow$ & Câmbio, lag(1) & $F(1,96)=1,1168796$ \\
\hline Serra & $\longrightarrow$ & Câmbio, lag(2) & $F(2,94)=1,8943557$ \\
\hline Serra & $\longrightarrow$ & Ibovespa, lag(1) & $F(1,96)=0,31256575$ \\
\hline Serra & $->$ & Ibovespa, lag(2) & $F(2,94)=1,2548266$ \\
\hline Serra & $\longrightarrow$ & C-Bond, lag(1) & $F(1,96)=0,35536623$ \\
\hline Serra & $->$ & C-Bond, lag(2) & $F(2,94)=1,1515653$ \\
\hline
\end{tabular}

Fonte: Banco de Dados Economia e Eleições - Rennó e Spanakos.

${ }^{*}$ sign. $0,1,{ }^{* *}$ sign. $0,05,{ }^{* * *}$ sign. 0,01 .

intenções de voto de todos os demais candidatos que concorreram em 1994, 1998 e 2002 são combinadas em uma só variável. Uma limitação dessa escolha é que há perda em detalhamento na análise dos determinantes econômicos e políticos da variação na intenção de voto dos candidatos incluídos na categoria residual. Uma vantagem é que essa codificação da variável reduz o problema de dados ausentes ${ }^{17}$.

O motivo para resumir o total de informação existente nas categorias constantes da Tabela 2 é diminuir o número de casos ausentes e aumentar o tamanho da amostra analisada. Em vez de analisar cada ano elei- 
toral separadamente, o que diminuiria o tamanho da amostra e inviabilizaria comparações entre os distintos anos (por causa dos tamanhos diferentes de amostra para cada ano), optamos por abrir mão de um grande detalhamento em nome de aumentar a generalização dos achados.

Um lado positivo da codificação adotada é a inclusão das intenções de voto em branco e nulo e da porcentagem de indecisos, o que permite ampliar as inferências feitas acerca do impacto da economia nas intenções de voto. Como bem argumenta Stokes (2001:23-25), ambivalência quanto ao governo e agnosticismo também podem ser afetados pelo estado da economia, principalmente em países onde a situação econômica é instável e complexa. Nestes casos, a complexidade da economia e sua baixa previsibilidade podem levar a um embaçamento da atribuição de responsabilidades e a uma maior dificuldade de compreensão sobre a relação entre economia e política, o que pode gerar ambivalência e agnosticismo. Se, por um lado, a análise abaixo perde informação por agrupar os candidatos com pouco apoio eleitoral em uma categoria residual, ela ganha em muito incorporando a ambivalência eleitoral, instrumentalizada pelo número de indecisos, e o agnosticismo, operacionalizado pela intenção de votar em branco ou nulo.

As variáveis independentes econômicas (inflação, desemprego, taxa de câmbio e Ibovespa), foram defasadas em uma unidade de observação (data da divulgação da pesquisa eleitoral) para melhor aproveitar a natureza dinâmica das séries temporais. Ou seja, será analisado se os indicadores da economia de fato antecedem alterações nas escolhas eleitorais e se esse impacto existe mesmo levando-se em conta diversas outras causas ${ }^{18}$.

Com relação às variáveis políticas, há uma diferença entre as equações. Para a equação que explica o voto em candidatos do governo, Fernando Henrique e Serra, foi acrescentada uma variável dummy para avaliar o impacto da campanha da reeleição nas escolhas eleitorais. A variável Reeleição tem valor 1 para todas as pesquisas realizadas em 1998 e visa a identificar se este ano eleitoral foi distinto dos outros dois, nos quais Fernando Henrique em 1994 e Serra em 2002 competiam por um primeiro mandato. Todas as equações contêm variáveis dummy para pesquisas divulgadas durante o HGPE e para pesquisas que ocorrem posteriormente a debates entre os candidatos a presidente.

As equações também contêm um indicador de popularidade do presidente (RESPOP), medido inicialmente pelas pesquisas de opinião e 
modificado para ser acrescentado ao modelo. A variável RESPOP é uma variável latente para popularidade presidencial atribuída a fatores não-econômicos. Ela é simplesmente o resíduo de uma equação de mínimos quadrados que tem como variável dependente a popularidade presidencial mensal e como variáveis independentes os indicadores econômicos mencionados anteriormente. Portanto, essa variável é um indicador de popularidade do presidente excluindo o impacto de variáveis econômicas. Trata-se de uma variável de popularidade baseada exclusivamente em fatores outros que o desempenho do presidente na economia, como carisma pessoal, por exemplo ${ }^{19}$.

Por fim, um controle para o instituto de pesquisa que realizou a aferição da intenção de voto foi acrescentado na análise e esse é necessário para evitar que algum fator extrapolítico ou extra-econômico influencie nos resultados ${ }^{20}$.

Fica claro que a porcentagem da variança explicada para cada equação é bastante alta. O modelo proposto reduz os erros na predição das intenções de voto para Lula, candidatos do governo e votos em branco acima de $80 \%$. Fica claro também que a escolha melhor explicada pelo modelo é o voto em candidatos do governo (Fernando Henrique e Serra).

Primeiro vejamos o impacto das variáveis políticas. O HGPE afetou positivamente as intenções de voto nos candidatos do governo e negativamente nos candidatos englobados na categoria Outros. Em ambos os casos, esses coeficientes são estatisticamente significativos. $\mathrm{O}$ HGPE também reduziu a tendência de se votar em branco e nulo, favoreceu os candidatos do governo, prejudicou os candidatos que se apresentavam como uma alternativa a Lula na oposição e reduziu o agnosticismo.

Interessante notar que os debates entre candidatos a presidente influenciam o voto apenas nos candidatos do governo. As intenções de voto em Fernando Henrique e Serra são positivamente influenciadas pelos debates. Em nenhum outro caso os debates influenciaram escolhas eleitorais. Portanto, a performance dos candidatos do governo nos debates colaborou com o aumento de seu apelo popular.

A variável RESPOP - popularidade presidencial excluindo o impacto de variáveis econômicas -, quando significativa, tem o efeito positivo esperado na intenção de voto nos candidatos do governo e negativo nos demais candidatos incluídos na categoria Outros. Novamente, os 
Tabela 2

Seemingly Unrelated Regression para Intenção de Voto

Brasil: 1994, 1998 e 2002

\begin{tabular}{|c|c|c|c|c|c|c|}
\hline Equation & Obs & Parms & RMSE & "R-sq" & chi2 & $\mathbf{P}$ \\
\hline Lula & 67 & 9 & 0,048481 & 0,8323 & 332,57 & 0,0000 \\
\hline Governo & 67 & 10 & 0,0395162 & 0,8939 & 696,09 & 0,0000 \\
\hline Outros & 67 & 9 & 0,0914469 & 0,4767 & 61,04 & 0,0000 \\
\hline Branco & 67 & 9 & 0,011138 & 0,8379 & 346,40 & 0,0000 \\
\hline \multirow[t]{2}{*}{ Indeciso } & 67 & 9 & 0,0176326 & 0,6691 & 135,46 & 0,0000 \\
\hline & Coef, & Std, Err, & z & $P>|z|$ & \multicolumn{2}{|c|}{ [95\% Conf, Interval] } \\
\hline \multicolumn{7}{|l|}{ Lula } \\
\hline Ibope & $-0,0733355$ & 0,0329418 & $-2,23$ & 0,026 & $-0,1379003$ & $-0,0087708$ \\
\hline Datafolha & $-0,1019559$ & 0,0325992 & $-3,13$ & 0,002 & $-0,1658492$ & $-0,0380626$ \\
\hline HGPE & $-0,0139848$ & 0,0161286 & $-0,87$ & 0,386 & $-0,0455963$ & 0,0176267 \\
\hline Debate & 0,0013895 & 0,025533 & 0,05 & 0,957 & $-0,0486542$ & 0,0514332 \\
\hline Respop & 0,0012473 & 0,0012858 & 0,97 & 0,332 & $-0,0012729$ & 0,0037675 \\
\hline Inflação & 0,0039658 & 0,0007957 & 4,98 & 0,000 & 0,0024063 & 0,0055252 \\
\hline Desemprego & 0,0086086 & 0,0104284 & 0,83 & 0,409 & $-0,0118306$ & 0,0290478 \\
\hline Câmbio & 0,099422 & 0,0081136 & 12,25 & 0,000 & 0,0835196 & 0,1153245 \\
\hline Ibovespa & $-9,48 e-06$ & $4,47 e-06$ & $-2,12$ & 0,034 & $-0,0000183$ & $-7,13 e-07$ \\
\hline _cons & 0,2275558 & 0,075092 & 3,03 & 0,002 & 0,0803782 & 0,3747334 \\
\hline \multicolumn{7}{|l|}{ Governo } \\
\hline Reelection & 0,2839927 & 0,0202022 & 14,06 & 0,000 & 0,244397 & 0,3235883 \\
\hline Ibope & $-0,0339893$ & 0,0263569 & $-1,29$ & 0,197 & $-0,085648$ & 0,0176693 \\
\hline Datafolha & $-0,0578664$ & 0,0259337 & $-2,23$ & 0,026 & $-0,1086955$ & $-0,0070374$ \\
\hline HGPE & 0,0444454 & 0,0131698 & 3,37 & 0,001 & 0,018633 & 0,0702577 \\
\hline Debate & 0,0351723 & 0,0204425 & 1,72 & 0,085 & $-0,0048942$ & 0,0752389 \\
\hline Respop & 0,0048914 & 0,0010294 & 4,75 & 0,000 & 0,0028738 & 0,006909 \\
\hline Inflação & $-0,0037838$ & 0,0006354 & $-5,96$ & 0,000 & $-0,0050291$ & $-0,0025385$ \\
\hline Desemprego & $-0,08824$ & 0,0108881 & $-8,10$ & 0,000 & $-0,1095802$ & $-0,0668998$ \\
\hline Câmbio & 0,014402 & 0,0088593 & 1,63 & 0,104 & $-0,0029618$ & 0,0317659 \\
\hline Ibovespa & $2,48 \mathrm{e}-06$ & $3,66 e-06$ & 0,68 & 0,497 & $-4,69 e-06$ & $9,66 e-06$ \\
\hline _cons & 0,8861381 & 0,0662553 & 13,37 & 0,000 & 0,7562802 & 1,015996 \\
\hline \multicolumn{7}{|l|}{ Outros } \\
\hline Ibope & 0,1862444 & 0,0621362 & 3,00 & 0,003 & 0,0644598 & 0,3080291 \\
\hline Datafolha & 0,1665781 & 0,06149 & 2,71 & 0,007 & 0,04606 & 0,2870962 \\
\hline HGPE & $-0,0651653$ & 0,0304224 & $-2,14$ & 0,032 & $-0,1247922$ & $-0,0055384$ \\
\hline Debate & $-0,0624864$ & 0,0481613 & $-1,30$ & 0,194 & $-0,1568809$ & 0,0319081 \\
\hline
\end{tabular}

(continua) 
Fundamentos da Economia, Mercado Financeiro e Intenção de Voto...

Tabela 2

Seemingly Unrelated Regression para Intenção de Voto

Brasil: 1994, 1998 e 2002

(continuação)

\begin{tabular}{|c|c|c|c|c|c|c|}
\hline & Coef, & Std, Err, & z & $P>|z|$ & \multicolumn{2}{|c|}{ [95\% Conf, Interval] } \\
\hline Respop & $-0,0082104$ & 0,0024254 & $-3,39$ & 0,001 & $-0,0129641$ & $-0,0034567$ \\
\hline Inflação & 0,000445 & 0,0015008 & 0,30 & 0,767 & $-0,0024966$ & 0,0033865 \\
\hline Desemprego & $-0,0141552$ & 0,0196704 & $-0,72$ & 0,472 & $-0,0527085$ & 0,024398 \\
\hline Câmbio & 0,027805 & 0,0153043 & 1,82 & 0,069 & $-0,0021908$ & 0,0578008 \\
\hline Ibovespa & 0,0000161 & $8,44 e-06$ & 1,91 & 0,057 & $-4,50 e-07$ & 0,0000326 \\
\hline cons & $-0,0492178$ & 0,1416415 & $-0,35$ & 0,728 & $-0,3268301$ & 0,2283945 \\
\hline \multicolumn{7}{|l|}{ Branco } \\
\hline Ibope & $-0,0126762$ & 0,0075681 & $-1,67$ & 0,094 & $-0,0275093$ & 0,002157 \\
\hline Datafolha & $-0,0085393$ & 0,0074893 & $-1,14$ & 0,254 & $-0,0232182$ & 0,0061395 \\
\hline HGPE & $-0,0079093$ & 0,0037054 & $-2,13$ & 0,033 & $-0,0151717$ & $-0,0006469$ \\
\hline Debate & $-0,0051538$ & 0,0058659 & $-0,88$ & 0,380 & $-0,0166509$ & 0,0063432 \\
\hline Respop & 0,000141 & 0,0002954 & 0,48 & 0,633 & $-0,000438$ & 0,00072 \\
\hline Inflação & 0,0009337 & 0,0001828 & 5,11 & 0,000 & 0,0005754 & 0,0012919 \\
\hline Desemprego & 0,0089257 & 0,0023958 & 3,73 & 0,000 & 0,00423 & 0,0136214 \\
\hline Câmbio & $-0,0240604$ & 0,001864 & $-12,91$ & 0,000 & $-0,0277139$ & $-0,020407$ \\
\hline Ibovespa & $2,62 \mathrm{e}-06$ & $1,03 \mathrm{e}-06$ & 2,55 & 0,011 & $6,06 \mathrm{e}-07$ & $4,64 \mathrm{e}-06$ \\
\hline _cons & 0,0403296 & 0,0172516 & 2,34 & 0,019 & 0,006517 & 0,0741422 \\
\hline \multicolumn{7}{|l|}{ Indeciso } \\
\hline Ibope & $-0,024797$ & 0,0119809 & $-2,07$ & 0,038 & $-0,0482792$ & $-0,0013147$ \\
\hline Datafolha & 0,0210848 & 0,0118564 & 1,78 & 0,075 & $-0,0021532$ & 0,0443228 \\
\hline HGPE & $-0,0007994$ & 0,005866 & $-0,14$ & 0,892 & $-0,0122965$ & 0,0106977 \\
\hline Debate & $-0,0060092$ & 0,0092864 & $-0,65$ & 0,518 & $-0,0242102$ & 0,0121917 \\
\hline Respop & 0,0000153 & 0,0004677 & 0,03 & 0,974 & $-0,0009013$ & 0,0009319 \\
\hline Inflação & $-0,0002728$ & 0,0002894 & $-0,94$ & 0,346 & $-0,00084$ & 0,0002944 \\
\hline Desemprego & $-0,0067672$ & 0,0037928 & $-1,78$ & 0,074 & $-0,014201$ & 0,0006665 \\
\hline Câmbio & $-0,0166348$ & 0,0029509 & $-5,64$ & 0,000 & $-0,0224186$ & $-0,0108511$ \\
\hline Ibovespa & $1,04 \mathrm{e}-06$ & $1,63 e-06$ & 0,64 & 0,523 & $-2,15 e-06$ & $4,23 e-06$ \\
\hline _cons & 0,1742829 & 0,027311 & 6,38 & 0,000 & 0,1207544 & 0,2278115 \\
\hline
\end{tabular}

candidatos do governo se beneficiaram de outra variável de cunho puramente político - a popularidade do presidente.

A dummy para reeleição também tem efeito estatístico e substantivo muito forte nas intenções de voto de candidatos do governo. Fernando Henrique lucrou muito por se candidatar à reeleição. Todo o investi- 
mento feito para a aprovação da emenda constitucional que autoriza a reeleição não foi em vão. A eleição de 1998 foi distinta das demais, pois aumentou muito a chance de o candidato do governo ganhar.

Já o voto em Lula parece independente das variáveis de natureza política incluídas no modelo. O voto em Lula, na verdade, é afetado por três variáveis econômicas: ele se beneficia com o aumento na inflação e com uma maior defasagem do câmbio. Aumentos na Bolsa de Valores de São Paulo levam a um decréscimo de apoio a Lula, ou seja, o voto em Lula é influenciado tanto por indicadores dos fundamentos da economia quanto por indicadores do mercado financeiro e, em ambos os casos, prevalece a idéia do voto retrospectivo. Ou seja, quando a economia vai mal, as intenções de voto em Lula sobem; quando a economia dá sinais de recuperação, os votos em Lula caem.

A direção do efeito das variáveis econômicas discutidas acima é diametralmente oposta na intenção de voto em candidatos do governo e da oposição, conforme previsto na hipótese 3. Já o mesmo não pode ser dito com relação ao efeito da taxa de câmbio. O câmbio tem impacto idêntico no voto em Lula e nos candidatos do governo. Pioras na taxa de câmbio e desvalorização do Real afetam as intenções de voto em Lula e nos candidatos do governo de forma positiva. Quando a taxa de câmbio sobe, também sobe o voto em candidatos do governo.

Como explicar que o câmbio tem o mesmo efeito nas intenções de voto para distintos candidatos? Uma possível interpretação é que o reflexo das taxas de câmbio nas intenções de voto tenha significados diferentes para eleitores de distintos candidatos. O efeito positivo da taxa de câmbio no voto em candidatos do governo pode significar uma postura de exoneração, isto é, a culpa pela taxa de juros subir não é apenas do presidente e ele não é punido por isso. Pode, ainda, ser indício de que o eleitor emprega um cálculo intertemporal, acreditando que o aumento da taxa de câmbio é sinal que o governo é responsável e que melhorias virão no longo prazo.

Em uma visão oposta, desvalorização da moeda pode ser vista com uma indicação que a economia vai mal e isto leva ao aumento do apoio à oposição. Em suma, o impacto dúbio da taxa de câmbio, que não discrimina eleitores que apóiam o governo dos que apóiam a oposição, pode indicar que essa variável ativa cálculos de eleitores distintos em distintos eleitores. $\mathrm{O}$ fato de a taxa de câmbio apresentar tal resultado confirma em parte o argumento de Stokes que, em economias em trans- 
formação, o impacto de algumas variáveis é mais complexo do que inicialmente esperado. A mesma variável pode ter significados diferentes para distintos eleitores ${ }^{21}$.

\section{CONCLUSÃO}

Neste estudo foram testadas quatro hipóteses referentes à relação entre indicadores econômicos e intenção de voto nas eleições presidenciais brasileiras de 1994, 1998 e 2002. Usando um banco de dados único, ficou constatado que há uma relação causal de mão dupla entre indicadores macroeconômicos e do mercado financeiro, por um lado, e intenção de voto em Fernando Henrique, por outro. Já no caso de Serra, intenções de voto são predominantemente afetadas pela economia e não há uma relação de mão dupla. Intenções de voto em Lula, por sua vez, afetam as avaliações de risco-país (spread do C-bond) e são afetadas também por indicadores do mercado financeiro, taxa de câmbio e Ibovespa, assim como pela inflação.

Os achados dos testes SUR multivariados indicam que prevalece um padrão de voto retrospectivo no Brasil. Quando a economia vai mal, as intenções de voto nos candidatos do governo são afetadas negativamente e as intenções de voto em candidatos da oposição positivamente. Ao contrário do que argumenta Stokes para o caso peruano, e de forma similar ao caso argentino estudado por Echegaray e Elordi (2001) e ao mexicano por Buendía Laredo (2001), intenções de voto no Brasil são influenciadas pela economia seguindo um padrão previsto pela teoria do voto retrospectivo.

(Recebido para publicação em fevereiro de 2005)

(Versão definitiva em março de 2006) 


\section{NOTAS}

1. Há diversos estudos que enfocam o papel de variáveis financeiras (taxa de câmbio, taxa de juros, bolsa de valores) em países desenvolvidos. Tais estudos serão abordados a seguir.

2. Nas eleições de 1994 e 1998, a inflação foi o principal tema econômico na agenda eleitoral.

3. A maioria dos modelos de economia política, principalmente o debate sobre ciclos eleitorais (Nordhaus, 1975; Alesinae et alii 1997; Remmer, 1993), assume que esse tipo de voto é predominante. Stokes (2001) chega a afirmar que o voto retrospectivo é o tipo de voto normal em um regime democrático estável.

4. Avaliações prospectivas baseiam-se em expectativas quanto ao futuro e voltam-se principalmente para as propostas políticas dos candidatos e não para seu desempenho em cargos anteriores.

5. Accountability é aqui entendida como a capacidade de o eleitor punir governantes que não desempenham satisfatoriamente suas tarefas (Przeworski et alii 1999).

6. Segundo Alesina et alii (1997), tais partidos tendem a privilegiar o combate ao desemprego em vez do controle da inflação, já que privilegiam estratégias de redistribuição de renda que favorecem classes mais baixas. Tal característica cria brechas para a volta de ciclos populistas, nos quais pressões distributivistas de curto prazo ganham respaldo na agenda governamental (Haggard e Kaufman, 1992).

7. Concordamos com Lewis-Beck (1988) quando diz que há problemas de se fazer inferências do nível agregado para o individual. Mas como ele, achamos que a análise agregada oferece um tipo de informação que raramente é obtida no plano individual - as séries temporais. Por isso, ambas as abordagens são úteis para o entendimento da relação entre economia e voto.

8. Ver Hibbs (1987) e Stokes (2001) para uma discussão sobre a curva de Phillips. Contudo, a curva de Phillips não explica a trajetória da economia brasileira durante a época de alta inflação, particularmente entre 1983 e 1993, quando um crescimento na inflação se correlacionou com sua diminuição. Só depois da estabilização, a curva de Phillips começou a ser aplicável ao Brasil.

9. Segundo Spanakos (2002), a dubiedade do discurso eleitoral do PT, ora pregando mudanças radicais, ora a manutenção de contratos, também contribuiu para aumentar a incerteza dos analistas do mercado financeiro e as oscilações negativas dos indicadores deste.

10. O spread do C-bond é a diferença entre os títulos da dívida externa brasileira e os títulos da dívida pública do governo norte-americano. Esse último indicador é considerado livre de risco, pois é muito baixa a probabilidade de o governo norte-americano não honrar seus papéis. $\mathrm{O}$ valor da diferença, portanto, indica quantos investidores estão interessados em receber a mais pelos títulos da dívida brasileira. Quanto maior a diferença, maior o risco de investimento no país. O interessante é que o spread só é calculado para países em desenvolvimento. Para os países desenvolvidos, há paridade entre os juros pagos pelos bonds, quando estes estão denominados em uma mesma moeda. Ou seja, o spread do C-bond é uma medida por excelência de como a economia de um país em desenvolvimento é avaliada pelo mercado financeiro internacional. Já o Índice da Bolsa de Valores de São Paulo é o mais importante indicador do de- 
sempenho das cotações do mercado de ações brasileiro. O Ibovespa é um termômetro do comportamento dos principais papéis negociados na Bolsa de São Paulo. Ele também indica a confiança de investidores na capacidade produtiva das empresas que negociam suas ações na Bolsa.

11. O enfoque deste artigo é no impacto de indicadores econômicos. As variáveis políticas, embora importantes, são vistas aqui como controles acrescentados ao modelo principalmente para evitar vieses causados por erros de especificação. Sem dúvida, estudos futuros devem enfocar aspectos políticos de forma mais detalhada.

12. Todas as séries utilizadas são estacionárias, com resultados de testes Dikey Fuller acima de $-3,0$ em um intervalo de confiança de $1 \%$.

13. As séries temporais para cotação do dólar no câmbio comercial para venda, Índice da Bolsa de Valores de São Paulo e spread do C-bond são diárias. As séries para inflação, desemprego e renda média são mensais.

14. Intenções de voto em distintos candidatos medidas como porcentagens agregadas são um bom exemplo de variáveis composicionais. Os erros de estimação dessas variáveis estão correlacionados. Analisá-las separadamente, utilizando regressão de mínimos quadrados, levaria a vieses nos coeficientes, por isso utilizamos Seemingly Unrelated Regression - SUR. Também usamos testes de Granger bivariado, que, por apenas realizarem testes de significância estatística, não sofrem problema de correlação dos erros-padrão e permitem que cada série temporal seja analisada separadamente.

15. Os testes de Granger bivariados apresentados anteriormente satisfazem dois critérios necessários para a identificação de relações causais: 1) antecedência temporal, obtida através do uso de variáveis defasadas; e 2) covariação, estimada por testes de significância estatística. Contudo, para estabelecer causalidade há a necessidade de satisfazer um terceiro critério: ausência de explicações espúrias. Só um teste multivariado evita espuriedade, pois testa o impacto de uma variável independente na dependente, controlando por outras variáveis. Além disso os testes de Granger realizam apenas um teste de associação, sem identificar a direção da relação (se positiva ou negativa) e sem estipular a magnitude dos efeitos (tamanho dos coeficientes). Nesse sentido, testes multivariados são mais robustos, informativos e confiáveis do que os bivariados.

16. A primeira vista, as séries temporais de intenção de voto em Lula, Serra e Fernando Henrique parecem ser independentes uma da outra. Isso não é totalmente verdadeiro. Em uma análise de regressão multivariada, os erros-padrão de uma escolha eleitoral estão correlacionados com os erros de outra escolha. Portanto, intenções de voto nos diversos candidatos não podem ser analisadas em um modelo multivariado independentemente umas das outras. Devem sim ser analisadas em uma série de equações lineares conjuntas. Por esse motivo, apenas o SUR permite a estimação de coeficientes e erros-padrão sem vieses e eficientes. A análise Granger Bivariada não é afetada por esses problemas, pois não estima coeficientes, apenas realiza um teste $\mathrm{F}$ de significância estatística para verificar se a hipótese nula, uma variável não causa a outra, é rejeitada. Já testes VAR (Vetores Auto-regressivos), que permitiriam testar o impacto das intenções de voto nas variáveis econômicas em um modelo multivariado, necessariamente enfocariam apenas cada uma das escolhas eleitorais separadamente, o que os tornariam sensíveis ao problema de correlação dos erros. Por esse motivo optamos pelo modelo SUR de estimação e os testes de causalidade de 
Granger em vez de VAR. Além disso, seguindo sugestões de Katz e King (1999) e Stokes (2001), o modelo SUR também foi rodado com as variáveis dependentes transformadas em uma distribuição logística multivariada para eliminar restrições criadas pela natureza intervalar das variáveis de intenção de voto. Os resultados apresentados a seguir, no entanto, estão embasados nas variáveis dependentes em sua métrica natural, porcentagens. Os resultados obtidos com tal métrica não diferem dos obtidos quando as variáveis dependentes são transformadas e a interpretação dos coeficientes é mais fácil mantendo a métrica natural das variáveis dependentes (ver Stokes (2001) e King e Katz (1999) para mais detalhes).

17. Nem todos os candidatos que compõem a categoria Outros concorreram em todas as eleições. Na verdade, apenas Ciro Gomes e Enéas Carneiro concorreram em duas eleições. Todos os demais candidatos, entre eles Anthony Garotinho, Orestes Quércia, concorreram em apenas uma. Para simplificar a análise e permitir uma avaliação de todos os anos eleitorais de 1994 a 2002, optamos por combinar o voto de todos esses candidatos em apenas uma categoria em vez de analisarmos cada um separadamente ou, pior ainda, excluí-los por completo da análise. Ao combinarmos todos em uma categoria residual, evitamos os problemas de dados ausentes e ainda sim os mantemos na análise, evitando vieses causados pela exclusão dos mesmos por causa da correlação entre os erros dessa variável com o das demais variáveis dependentes.

18. Não incluímos a variável C-bond na análise, pois só temos dados disponíveis para ela para as eleições de 1998 e 2002. Contudo, outros indicadores presentes, como o Índice da Bovespa e a taxa de câmbio permitem fazer inferências sobre o impacto do mercado financeiro nas intenções de voto.

19. $O R^{2}$ ajustado na equação que explica a popularidade presidencial é 0,86 . Ou seja, quase toda a popularidade do presidente é resultado de seu desempenho na economia. Os restantes $14 \%$ devem-se a fatores outros, como seu carisma pessoal, seu partido político etc.

20. Também acrescentamos um controle para diferenciar pesquisas feitas no primeiro e segundo turnos em 2002. Em 1994 e 1998, não houve segundo turno. Essa variável é significativa, mas não foi incluída nas equações abaixo porque não tem qualquer interesse teórico e os resultados das demais variáveis não são afetados pela inclusão ou ausência da variável sobre segundo turno.

21. Essa é uma excelente hipótese a ser testada usando dados de levantamentos de opinião pública em âmbito individual. O fato de o impacto do câmbio ser idêntico para todos os candidatos, quando inflação e desemprego são controlados, pode indicar apenas que câmbio é usado como uma forma de racionalizar o voto, de apresentar justificativas para escolhas ideológicas preexistentes (Maravall e Przeworski, 2001). 
Fundamentos da Economia, Mercado Financeiro e Intenção de Voto...

\section{REFERÊNCIAS BIBLIOGRÁFICAS}

ALESINA, Alberto, ROUBINI, Nouriel e COHEN, Gerald. (1997), Political Cycles and the Macroeconomy. Cambridge, MA, MIT Press.

ANDERSON, Christopher e TVERDOVA, Yuliya. (2001), "The Economy and Public Opinion in East Germany After the Wall", in S. Stokes (org.), Public Support for Market Reforms in New Democracies. Cambridge, Cambridge University Press.

BASINGER, Scott e HALLERBERG, Mark. (2004), “Remodeling the Competition for Capital: How Domestic Politics Erases the Race to the Bottom". American Political Science Review, vol. 98, nํ2, pp. 261-276.

BERNHARD, William e LEBLANG, David. (2001), Polls and Pounds: Public Opinion and Exchange Rate Volatility in Britain. Manuscrito.

BERRY, Brian, ELLIOTT, Euel e HARPHAM, Edward. (1996), "The Yield Curve as an Electoral Bellwether". Technological Forecasting and Social Change, vol. 51, pp. 281-294.

BORSANI, Hugo. (2001), “Eleições e Desempenho Macroeconômico na América Latina (1979-1998)". Dados, vol. 44, nº 3, pp. 481-512.

BUENDÍA LAREDO, Jorge. (2001), “Economic Reforms and Political Support in Mexico, 1988-1997", in S. Stokes (org.), Public Support for Market Reforms in New Democracies. Cambridge, Cambridge University Press.

CAMARGOS, Malco B. (2001), “Economia e Voto: Fernando Henrique Versus Lula, 1998". Teoria e Sociedade, no 8, pp. 116-145.

CARREIRÃO, Yan. (2002), A Decisão de Voto nas Eleições Presidenciais Brasileiras. Rio de Janeiro, Fundação Getulio Vargas Editora.

CLARK, William R. e HALLERBERG, Mark. (2000), “Mobile Capital, Domestic Institutions, and Electorally Induced Monetary and Fiscal Policy". American Political Science Review, vol. 94, nํㅡ 2, pp. 323-346.

DOWNS, Anthony. (1957), An Economic Theory of Democracy. New York, Harper.

ECHEGARAY, Fabian. (1995), “Voto Econômico ou Referendum Político? Os Determinantes das Eleições Presidenciais na América Latina, 1982-1994". Opinião Pública, vol. $3, \mathrm{n}^{\mathrm{o}} 2$.

e ELORDI, Carlos. (2001), “Public Opinion, Presidential Popularity, and Economic Reform in Argentina, 1989-1996", in S. Stokes (org.), Public Support for Market Reforms in New Democracies. Cambridge, Cambridge University Press.

EULAU, Heinz e LEWIS-BECK, Michael (eds.). (1985), Economic Conditions and Electoral Outcomes: The United States and Western Europe. New York, Agathon Press.

FIORINA, Morris. (1981), Retrospective Voting in American National Elections. New Haven, Yale University Press.

FREEMAN, John, HAYS, Jude e STIX, Helmut. (2000), “Democracy and Markets: The Case of Exchange Rates". American Journal of Political Science, vol. 44, no 3, pp. 449-468.

GLEISNER, Richard. (1992), “Economic Determinants of Presidential Elections: The Fair Model". Political Behavior, vol. 14, no 4, pp. 383-394. 
HAGGARD, S. e KAUFMAN, R. (1992), “Economic Adjustment and the Prospects for Democracy", in S. Haggard e R. Kaufman (eds.), The Politics of Economic Adjustment. Princeton, Princeton University Press.

HAYS, Jude, STIX, Helmut e FREEMAN, John. (2000), The Electoral Information Hypothesis Revisited. Trabalho apresentado na conferência Globalization and Democracy, University of Minesota, 26-27 de maio.

HIBBS, Douglas. (1987), The American Political Economy. Cambridge, MA, Harvard University Press.

KATZ, Jonathan e KING, Gary. (1999), “A Statistical Model for Multiparty Electoral Data". The American Political Science Review, vol. 93, nํำ.

KAUFMAN, Robert e SEGURA-UBIERGO, Alex. (2001), “Globalização, Política Interna e Gasto Social na América Latina: Uma Análise de Corte Transversal com Série Temporal, 1973-1997". Dados, vol. 44, no 3, pp. 435-479.

LEBLANG, David. (1997), “Domestic and Systemic Determinants of Capital Controls in the Developed and Developing World". International Studies Quarterly, vol. 41, no 3, pp. 435-454.

LEWIS-BECK, Michael. (1988), Economics and Elections: The Major Western Democracies. Ann Arbor, The University of Michigan Press.

MARAVALL, José María e PRZEWORSKI, Adam. (2001), “Political Reactions to the Economy: The Spanish Experience", in S. Stokes (ed.), Public Support for Market Reforms in New Democracies. Cambridge, Cambridge University Press.

MENDES, Antônio e VENTURI, Gustavo. (1994), “Eleição Presidencial: O Plano Real na Sucessão de Itamar Franco". Opinião Pública, vol. 2, no 2.

MENEGUELLO, Rachel. (1994), “Partidos e Tendências de Comportamento: O Cenário Político em 1994", in E. Dagnino (org.), Os Anos 90: Política e Sociedade no Brasil, São Paulo, Brasiliense, pp. 151-171, 1994.

MIGUEL, Luis Felipe. (1999), "Mídia e Eleições: A Campanha de 1998 na Rede Globo". Dados, vol. 42, no 2, pp. 253-276.

NORDHAUS, William. (1975), "The Political Business Cycle”. Review of Economic Studies, vol. 42, pp. 169-190.

O’DONNELL, Guillermo. (1994), “Delegative Democracy?”. Journal of Democracy, vol. 5, no 1 , pp. 55-69.

PRZEWORSKI, Adam. (2001), "Public Support for Economic Reforms in Poland", in S. Stokes (ed.), Public Support for Market Reforms in New Democracies. Cambridge, Cambridge University Press.

, STOKES, Susan, e MANIN, Bernard. (1999), Democracy, Accountability, and Representation. Cambridge, Cambridge University Press.

REMMER, Karen. (1993), “The Political Economy of Elections in Latin America, 1980-1991". American Political Science Review, vol. 87, no 2, pp. 393-407.

SINGER, André. (2000), Esquerda e Direita no Eleitorado Brasileiro: A Identificação Ideológica nas Disputas Presidenciais de 1989 e 1994. São Paulo, Edusp. 
SPANAKOS, Tony. (2002), “The Brazilian Elections: A View from Wall Street". Manuscrito não publicado.

STOKES, Susan. (2001), "Introduction: Public Opinion of Market Reforms: A Framework", in S. Stokes (ed.), Public Support for Market Reforms in New Democracies. Cambridge, Cambridge University Press, 2001.

. (2001a), "Economic Reforms and Public Opinion in Fujimori's Peru”, in S. Stokes (ed.), Public Support for Market Reforms in New Democracies. Cambridge, Cambridge University Press.

. (2001b), Mandates and Democracy: Neoliberalism by Surprise in Latin America. Cambridge, Cambridge University Press.

WILLIAMSON, John. (2002), “Is Brazil Next?”. Washington, D.C. Institute of International Economics, Policy Briefs PB02-7 Working papers.

\begin{abstract}
Economic Fundamentals, Financial Markets, and Voting Preferences: The 1994, 1998, and 2002 Brazilian Presidential Elections

This article explores the relationship between macroeconomic indicators, financial markets, and voting intentions in the 1994, 1998, and 2002 Brazilian Presidential elections. Several hypotheses concerning the relationship between economic performance and politics were tested using a data set containing aggregate measures of self-reported preferences for the Presidential candidates and economic indicators (inflation, unemployment, exchange rate, C-Bond spread, and the São Paulo Stock Exchange Index). The first hypothesis refers to the potential simultaneity between economic indicators and voting intentions. Other hypotheses relate to the varied impact of different economic indicators on the intention to vote for a specific Presidential candidate as opposed to others. The results indicate that retrospective voting, based on the performance of economic fundamentals and not the financial market, predominates in Brazil.
\end{abstract}

Key words: Presidential elections; economic indicators; election preferences 


\section{RÉSUMÉ}

Fondements de l'Économie, Marché Financier et Intention de Vote: Les Élections Présidentielles Brésiliennes de 1994, 1998 et 2002

Dans cet article, on analyse la relation entre indicateurs des fondements de l'économie brésilienne, du marché financier et de l'intention de vote pour les élections présidentielles de 1994, 1998 et 2002 au Brésil. À partir d'une banque de données formée d'évaluations comprenant l'intention de vote et des indicateurs économiques (inflation, chômage, taux de change, spread du C-Bond et chiffre de la Bourse de Valeurs de São Paulo) on a examiné plusieurs hypothèses sur le rapport entre économie et politique. La première hypothèse concerne la possible simultanéité entre indicateurs économiques du marché financier et intention de vote. D'autres hypothèses ont rapport à divers sens provoqués par l'impact de certains indicateurs économiques sur les intentions de vote des candidats en présence. Les résultats de l'analyse indiquent que, au Brésil, le facteur le plus déterminant est le calcul de vote essentiellement rétrospectif, basé sur la performance des fondements de l'économie et non pas sur les indicateurs du marché financier.

Mots-clé: élections présidentielles; indicateurs économiques; intention de vote 